\title{
A PENA COMO ARMA: TRABALHO, INTIMIDADE E ROTINA NAS CARTAS DOS POLICIAIS PAULISTAS (1870-1915)
}

The pen as a weapon: work, intimacy and routine in the letters of São Paulo's policemen (1870-1915)

ANDRE ROSEMBERG

http://dx.doi.org/10.1590/S2178-14942016000300004

Andre Rosemberg é mestre e doutor em História Social pela Universidade de São Paulo e pesquisador do Observatório da Segurança Pública do campus de Marília da Universidade Estadual Paulista (arosem1910@gmail.com).

Artigo recebido em 23 de agosto e aprovado para publicação em 29 de setembro de 2016. 


\title{
RESUMO
}

Por meio da análise das cartas escritas por policiais, pretendemos desvelar facetas pouco iluminadas da polícia de São Paulo no contexto histórico da virada do século XIX para o XX. Nas linhas desse instrumento tão pessoal, como são as cartas, vislumbram-se fragmentos da intimidade dos policiais, a presença da família, a porosidade entre os "mundos" civil e institucional. Desvelam-se na correspondência epistolar, pouco frequente numa estrutura burocrática, as estratégias desses trabalhadores na sua relação cotidiana com a instituição - o manejo pela sobrevivência num universo de pobreza e de iniquidades hierárquicas; enfim, as coxias do trabalho e da rotina policial.

Palavras-CHAVE: polícia; mundo do trabalho; história da polícia.

\begin{abstract}
Through the analysis of letters written by policemen, we intend to shed light on little known aspects of the São Paulo Police in the beginning of the XX century. This very personal mode of communication allows us to catch a glimpse of the intimacy of policemen's lives, the presence of family, the porosity between both civil and institutional "worlds". The epistolary form, so uncommon in a bureaucratic structure, uncovers the strategies of these workers in their daily relationship with the institution - the struggle for survival in a universe of poverty and hierarchical inequities; in short, a behind-the-scenes look into police work and routine.
\end{abstract}

KeYwORDs: police; labour; police history.

\section{RÉSUMÉ}

Par l'analyse de lettres écrites par des policiers, nous avons l'intention de dévoiler des aspects peu connus de la police de São Paulo dans le contexte historique du tournant du XIXème siècle. La nature personnelle de cet instrument permet d'entrevoir des fragments de l'intimité des policiers, la présence de la famille, la porosité entre les "mondes" civil et institutionnel. Ces documents épistolaires, peu communs dans une structure bureaucratique, dévoilent les stratégies de ces travailleurs dans leur relation quotidienne avec l'institution - la lutte pour la survie dans un univers de pauvreté et d'iniquités hiérarchiques; enfin, les coulisses du travail et de la routine policière.

MOTS-CLÉs: police: monde du travail; histoire de la police. 
m 24 de fevereiro de 1909, o secretário de Segurança Pública e de Negócios Jurídicos de São Paulo, Washington Luiz, recebeu em sua mesa de trabalho uma carta do tenente da Força Pública Joaquim José de Araújo, da 1aㅡ Companhia do 3ํㅡatalhão. 0 oficial, de 52 anos, casado e pai de três filhos, encontrava-se então lotado na capital do estado. A missiva trazia "em coleção um pequeno histórico" dos mais de 18 anos que havia dedicado aos serviços policiais.

Em 1877, teve a dura necessidade de abandonar o meu estado natal, Ceará, motivado por uma grande seca, fazendo esse trajeto todo a pé, atravessando diversos estados, passando privações horríveis, porque o meu estado de pobreza assim permitia, até que cheguei em Minas Gerais passando na cidade Januária. Só Deus sabe como... [...]. São decorridos 18 anos e meses de fadigado trabalho, falando somente neste estado [...]. Pois bem, como V. Exa vê do exposto que não basta somente a idade avançada como ao mesmo tempo as moléstias adquiridas no decorrer desses longos anos de luta, como sejam: reumatismo, retenção de urina, faltas de ar, finalmente sinto-me com os músculos cansados. No entanto, não estou impossibilitado de prestar o meu serviço ao estado, acreditando piamente no vosso elevado espírito de justiça e coração humanitário, [...] peço-vos portanto me dispensar das instruções adotadas [...].'

Duas considerações devem ser feitas a respeito desse episódio: a primeira é o instrumento escolhido pelo tenente Araújo para se comunicar com seu superior, uma carta; a segunda, decorrente da anterior, é o tom afetivo assumido pela narrativa. Constitui, sem dúvida, fato raro em relação ao conjunto da documentação policial a presença de cartas pessoais. Em sendo a polícia uma organização pautada na burocracia (Monjardet, 2001), e uma instituição que se pretende "total" - para emprestarmos o conceito de Goffmann (2003) -, a interlocução inter-hierárquica não deve prescindir das formalidades, da linguagem enquadrada e da estrutura precisa. Disso cuida a praxe policial, ao informar as normas de elaboração de ofícios e portarias.

0 presente texto pretende trazer à luz parte do material epistolar coligido nas latas de polícia do Arquivo Público do Estado de São Paulo entre os anos de 1870 e 1915, ${ }^{2}$ analisando-o sob uma perspectiva dupla: observando a prática epistolar em si mesma, que subsume o realce personalíssimo do "eu" - melhor dizendo, da "escrita de si" (Gomes, 2004) - num âmbito cerradamente institucional (a polícia de inclinação militar), e ao mesmo tempo lançando mão 
das sensibilidades de uma "história biográfica" que funciona como instrumento para realçar as subjetividades do homem comum, decalcando as individualidades da massa anônima, à qual costumam ser relegadas "as classes subalternas" nos estudos correspondentes (Loriga, 2007: 209).

Um estudo "epistológico" que tenha como base documental as fontes policiais, além de levar em conta as especificidades de método, deve questionar-se sobre quais os significados específicos que envolvem a eleição da carta como veículo de interlocução. Em geral, o uso das cartas como fonte implica a valorização do indivíduo em realce com o contexto, numa relação marcada pelas manifestações em primeira pessoa, "na qual o indivíduo assume uma posição reflexiva em relação à sua história e ao mundo onde se movimenta" (Malatian, 2009: 195). A carta configura-se no movimento dialético de afirmação do sujeito perante a instituição; aquele intercede nas ranhuras da capa normativa que se pretende inconsútil, impermeável às intencionalidades (Levy, 2009). Trata-se, a carta, de um duto de divulgação de demandas ou de descontentamentos e um meio de acionar canais alternativos de negociação. Ela põe em marcha uma afetividade, controlada - bem entendido -, a qual, ainda que escape por entre as tramas da rede da burocracia, se vê premida a submeter-se às regras de sociabilidade e à hierarquia que comandam as conexões operantes fora das (ou mesmo imbricadas às) redes mantidas pelo rigor institucional. E, assim, ela mobiliza repertórios alheios à normativa oficial, acionando operadores que vigoram no mundo de fora da polícia e que devem se curvar às expectativas vigentes - atender, enfim, a um código epistolar.

Em outro âmbito, a correspondência abre uma perspectiva metodológica bastante importante ao fazer emergirem a "voz" do policial - principalmente o de baixa patente - e as condições em que essa "voz" foi produzida. 0 acesso ao discurso do petit peuple é o graal de uma historiografia que se debruça sobre os "subalternos". Na maior parte das vezes, ele emerge escamoteado pela transcrição monocórdia de notários judiciais ou irremediavelmente obstado pela barreira da alfabetização.

Desvelar essa massa documental permite perfilar os policiais na mesma prosápia daqueles que normalmente se colocam como o público-alvo da ação policial, comungando com trabalhadores de todos os matizes, inseridos nos critérios os mais complacentes que lhes pespega uma condição comum, nas agruras de um cotidiano de faina, pobreza e luta pela sobrevivência. Este artigo faz parte de uma série mais longa que confere aos policiais o ingresso no "mundo do trabalho" (Rosemberg, 2015; 2015a; 2012; 2012a; 2010; 2009), numa proposta de estender-Ihes uma identidade que lhes é normalmente negada - a de trabalhador -, em nome de outra, reificada, restritora e meramente especular, tachados que são como 0 problema a ser confrontado (Rosemberg, 2012: 19-20). 
No mesmo diapasão, o presente texto dialoga com uma historiografia que, desde os anos 1980, reconhece o complexo lugar do policial nas dinâmicas sociais, compartilhando com outras ocupações - de forma tensionada e muitas vezes contraditória - a composição do universo do trabalho a partir do início do século XIX. Tal processo foi verificável em várias partes da Europa, dos Estados Unidos e da América Latina, em que pesem ritmos de implantação e "modelos" burocráticos diferentes, seja em âmbitos rurais ou urbanos. ${ }^{3}$

Veja-se o efeito a ser produzido pela lamentação do tenente Araújo ao descrever sua trajetória desditosa. Da pobreza nordestina à dignidade adquirida nas fileiras militares, a devoção de quase duas décadas à Força Pública, galgando patentes, forjado em disciplina férrea. Ao que parece, contudo, uma fé de ofício imaculada, de lisura irrepreensível, não serviria de adjutório para o oficial obter a dispensa das instruções, caso fossem seguidas as medidas prescritas pelos canais competentes. Apelou às intimidades, cevadas junto aos dirigentes nos anos de convivência, a fim de mover a máquina burocrática a seu favor.

Cabe ressaltar que a Força Pública, em 1909, estava sob os auspícios da Missão Francesa, contratada três anos antes aos pés do Exército francês com o fito de treinar a polícia paulista no modelo das escolas de Saumur e Saint Cyr. Os ventos que insuflaram no Quartel da Luz, sede principal da Força Pública, previam um programa completo de modernização e profissionalização da corporação, em destacado contraste com as práticas vigentes, associadas, ainda, ao arcaísmo do Império (Amaral, 1968).

0 tenente Araújo, do alto de seus 52 anos e do rol imodesto de moléstias de que afirmava padecer, talvez pretendesse se esquivar da nova ordem que passara a imperar sobre a rotina da milícia, enquadrando os oficiais num regime de trabalho mais puxado e especializado em relação ao anterior, consubstanciado, ao longo de décadas, no improviso do erro-e-acerto. A presença estrangeira também subvertia os arranjos hierárquicos que vigoravam até então, ao reforçar nexos relacionais pautados na estrita formalidade burocrática - como 0 mérito e a antiguidade -, descartando, ao mesmo tempo, critérios tradicionais sustentados em referenciais alheios (quando não em oposição) às normas a serem implementadas. A fim de escapar da liça novidosa, o tenente pôs em prática um expediente estranho aos novos princípios. Em vez de acionar os meios regulamentares - um ofício impessoal, enviado ao superior imediato, baseado em argumentos protocolares -, resolveu lançar mão de uma estratégia temerária, ao recorrer diretamente à última instância decisória por meio de uma rationale repleta de afetividade.

A prática de atalhar os trâmites normais, previstos na regra burocrática, para solicitar diretamente aos postos supremos da escala hierárquica, foi estratégia manejada especialmente pelos policiais de base. Espelhava, é verdade, um certo zeitgeist que regia as dinâmicas da 
sociedade imperial, assimetricamente hierárquica sob o peso da escravidão, e que se arrastou já no período republicano, em que a pessoalidade e o paternalismo ditavam o tom das relações, tanto na esfera privada como no âmbito público. Aspectos da boa convivência - seja no plano horizontal como no vertical - baseavam-se na habilidade de se dispor corretamente de recursos que jogavam com o privilégio, o prestígio, a proteção e a amizade (Chalhoub, 1998). Saber colocar-se numa posição otimizada perante o interlocutor, em relação de assimetria, consistia em arte a ser dominada pelo subalterno para lograr alguma vantagem. A leitura das cartas de policiais mostra uma tática roteirizada em que estes apelam para as mazelas de uma vida de pobreza, ao mesmo tempo em que se colocam em posição de subserviência, a atestar inequivocamente que o benefício requerido não se encontrava entre os direitos e deveres prescritos em normas universais, mas sim cabiam ao beneplácito de um "padrinho".

As fórmulas de endereçamento e de saudação escapam daquelas exigidas pela imposição burocrática - "Deus guarde V. Exa" no tempo do Império e "saúde e fraternidade", a partir do 15 de Novembro. ${ }^{4}$ Combinam, no lugar, uma fieira de substantivos e adjetivos que exaltam a figura do destinatário ao passo que rebaixam a posição do remetente, como no caso da carta escrita pelo praça Bento José Alves, "obediente e respeitador e subordinado de sua Excia", que vinha "juelhar-me nos peiz de sua Excia por me ver me em estado tão emfelis desgradaçadamente jugado no fundo desta prisão [... $]^{\prime \prime}$.

A carta do soldado Renato Ferreira Gonçalves enviada ao chefe de polícia em maio de 1901 talvez sumarize com precisão o ponto que quero apresentar:

\footnotetext{
Villa Americana 11 de maio de 1901

llustra dissimo e Dignissimo

Dr. Chefe de Polícia

Primeiramente ajoelho aos vossos pés, implorando o perdão por eu ter a ouzadia de vos escrever, sem ter corrido os canaes competentes e bem assim não estar na minha terra onde recebi o baptismo soffrendo as alguras da vida, sem ter um pae extremado e uma me [mãe] carinhoza!!!
}

Veem-se, nessa missiva, o apelo desesperado, o desvio dos trâmites prescritos, a linguagem subserviente. 0 soldado prefere estabelecer a conexão a partir de operadores alheios ao mundo institucional. Sua estratégia persuasiva não está nem mesmo qualificada no feixe discursivo avalizado pela esfera oficial. De fato, levadas as regras a ferro e fogo, seria descartado a priori, uma vez que não se compunha com a fórmula válida. Entretanto, a instituição mostra-se porosa a influências externas, e é acionada por vários repertórios que se interrelacionam. A "escrita de si", no sentido que Ihe empresta Foucault (2012) - a carta como 
elemento que impõe uma presença quase física do signatário diante do destinatário, uma troca simultânea de olhares -, é absorvida pela linguagem praxista e mostra-se um expediente eficiente nas mãos de praças no intuito de fazer mover a burocracia a seu favor.

À parte o teor das cartas, a apreciação holística do texto deve relevar os aspectos materiais e as condições gerais de produção do suporte em que a mensagem vem inscrita. Da qualidade do papel à precisão ortográfica, passando pelo capricho da caligrafia, percebe-se ao mesmo tempo o esforço despendido pelos policiais no exercício do convencimento e as limitações concretas para fazer chegar sua demanda ao destinatário final. Uma carta escrita de próprio punho tinha que transpor um obstáculo renitente: o da instrução básica. Nos regulamentos policiais saber ler e escrever não servia de critério excludente para o ingresso de recrutas, salvo na Companhia de Urbanos e, depois, na Guarda Cívica da Capital. É usual o fato de os policiais subscreverem cartas e abaixo-assinados "a rogo".

Muitos daqueles policiais que sobrestavam os impeditivos mais elementares viam-se obrigados a pelejar contra o vernáculo, a fim de dobrar as complexas regras ortográficas e sintáticas para fazerem entender as solicitações. Não é incomum depararmo-nos com caligrafias tensas, que se debatem para manter a retidão das frases na pauta. As letras, algumas vezes tortuosamente desenhadas, se esforçam para alinhavar um raciocínio persuasivo, seja apelando para argumentos formais, seja na tentativa de comover o destinatário.

\section{Motivos}

P elo fato de lidarmos com uma série rarefeita e intermitente de cartas, não nos é possível estabelecer uma tipologia exaustiva das motivações que levavam os policiais a lançar mão da correspondência epistolar. Ainda assim, algumas situações são mais assíduas na documentação pesquisada. Abrangendo um arco cronológico considerável, elas não se interrompem com as reformas de regulamento nem com a mudança do regime. Essas permanências, inclusive, passam a transgredir a normativa da polícia, que, no Regulamento 437, publicado em 20 de março de 1897, proíbe a manifestação pública dos policiais. ${ }^{7}$ Não obstante, tal prática - por meio de abaixo-assinados e missivas pessoais - não é abandonada pelos policiais.

Assim, podemos classificar os pedidos e demandas de policiais em quatro categorias. A primeira são queixas e reclamos contra superiores diretos que cometem injustiças ou perseguições. A segunda são pedidos de transferência, normalmente justificados pela distância da família e flagelos que afligiam parentes. A terceira refere-se a pedidos de baixa ou de licença, cuja justificativa devia obedecer aos estritos critérios regulamentares. A quarta categoria 
baseia-se em pedidos de perdão de praças presos correcionalmente ou condenados em Conselho de Justiça por faltas as mais diversas.

\section{QUEIXAS E RECLAMAÇÕES}

S e queixas e delações contra superiores diretos vincaram uma tática dos policiais de baixa patente para contornar abusos ou injustiças cometidas por comandantes imediatos, respaldada pela estrutura institucional que regulava estritamente os limites de competência e de ação de cada função, ao mesmo tempo, elas podiam funcionar como instrumento de pequenas nêmesis e compensações que regulavam as assimetrias hierárquicas que projetavam, de certa forma, as relações vigentes extramuros. Nesse caso, a instituição, longe de servir de anteparo ao mundo exterior, absorvia e emulava as mesmas práticas da esfera social. Quanto à forma, as manifestações podiam ser individuais ou coletivas, reveladas ou anônimas.

Além disso, um paradoxo se estabelece: o sistema oficial é utilizado como um meio de garantir que a relação superior-subordinado fosse respeitada. Se o comandante aplica obstinadamente o regulamento, arrisca-se a ferir práticas costumeiras de convivência regradas por uma rede normativa muito mais complacente. 0 contrário igualmente é possível: a conduta hors norme por parte do superior pode implicar reivindicação da parte do policial prejudicado no sentido de enquadrar a postura do superior dentro dos parâmetros regimentais.

Em 1872, uma carta anônima chegava à vista do chefe de polícia, denunciando o procedimento irregular do sargento comandante do destacamento de Tatuí. Lamentava que "não haverá um meio de corrigir o sargento comandante do destacamento desta cidade que vive roubando dos cofres públicos quantias superiores a que devia tirar para pagamento das praças que tem no destacamento e deixando de pagar a um pobre polícia como eu e outros mesmo as praças que aqui estiveram destacadas [...] fazendo tudo isto sem que haja um muito de ser corrigido por que o Delegado assina tudo quanto o sargento manda" . . A delação aparentemente rendeu frutos, uma vez que um inquérito policial foi aberto para averiguar a malversação do sargento, corroborada por duas testemunhas, policiais, que confirmaram o desvio do dinheiro recebido na coletoria de Sorocaba para o pagamento do soldo do destacamento.

Outra fonte comum de queixas eram os maus tratos de praças por parte de superiores diretos. Agiam, comandantes e delegados, de forma a desrespeitar as penas disciplinares estabelecidas no regulamento da corporação, infundindo para dentro do cerne institucional o comportamento arbitrário e sem mesuras acatado na arena social mais ampla. Em resposta, a reação não seguia necessariamente um cálculo utilitarista, prevendo a maximização do 
resultado. Ao contrário, as articulações mostravam-se complexas, remontando a lógicas multívocas e multicausais por trás da resposta do ofendido, variando da insubordinação violenta, que rebatia - olho por olho - a agressão sofrida, ao manejo sagaz dos mecanismos burocráticos, alternativa que a instituição lhes oferecia e cujos registros nos servem de fonte. Se a carta pessoal ou o abaixo-assinado não seguem ipsis literis o padrão prescrito pela normativa, ao menos servem de gatilho para desencadear a engrenagem hierárquica, desde o topo, em favor da reparação da injustiça.

De Araras, por exemplo, um abaixo-assinado enviado ao chefe de polícia por oito praças, em 1883, dava conta dos desmandos do cabo comandante do destacamento, que "vive bêbado toudos os dias e tem maltratado seus sobaternos sem motivo algum tem tirado a falda para brigar com o soldado José Francisco Rodrigues [...] por causa de prostituta [...]". .9 Nesse episódio, os policiais contaram com o apoio do delegado local que ratificou as queixas, afirmando que o cabo "tem se comportado de um modo de todo irregular [...] de sorte que elle se tem tornado incapaz de preencher as funções de seu cargo".

0 expediente do abaixo-assinado foi o instrumento de que lançou mão o destacamento de Ribeirão Preto, em fevereiro de 1888, para chamar a atenção do chefe de polícia em relação à conduta do comandante local:

Ilmo. Exmo Sr. Dr. chefe de polícia

Todas as praças pertencentes in este destacamento vem respeitozamente a V. Exa graça de dar providência sobre este pedido. 10 Este sargento trata as praças muito peior que negro captivo. 2- Pune as praças fora do prescritto regulamento; 3 sem saber os mottivo. As punições são as seguintes. Elle faz dobrar os pobre soldado na guarda 10 a 15 dias; faz marimbar 8 a 10 oras e ainda mais que elle provoca e maldi-las com palavras intolerables [...] Neste destacamento acha-se 10 pracas boa attivos ao servicio e ubedientes ao comte do destacamento [...] Se no per força succederão grande novidade com este sarcendo o que se ficará incorrigibel ou desertar tudos.

P. Benigno Defferimentos.

Somente que si assigna tudas as praças

A verdade de Deus ${ }^{10}$

Analisando-se as queixas aventadas contra o sargento, a que abre o rol das três parece ser a mais contundente: o tratamento pior do que o de negro cativo. Às vésperas da abolição, a homologia entre as circunstâncias de escravidão e o abuso disciplinar parecia ser um opróbrio inaceitável para os policiais, principalmente para os estrangeiros, provavelmente condição do subscritor. Durante o processo de constituição do Corpo Policial Permanente como a força policial paulista por excelência durante o último quartel do regime imperial, houve sempre um 
esforço retórico e funcional para distanciar o lugar social a ser ocupado pelo policial daquele impingido ao soldado do Exército (Rosemberg, 2010), que se via impregnado, nas várias esferas de representação, de uma situação análoga à dos escravos (Beattie, 2009). A exigência do engajamento voluntário (ao contrário do recrutamento compulsório inerente à tropa de linha) e a interdição explícita em regulamento da prestação de serviços pessoais visavam a afastar os praças de polícia do estigma do trabalho escravo. Agindo de forma atrabiliária, o sargento contraditava essa ordem de valores e dava vezo ao argumento incontestável: afinal o "espírito" institucional via-se ameaçado por essa aproximação indevida.

Outra carta coletiva, porém anônima, demonstra que as rusgas inter-hierárquicas não se arrefeceram no regime republicano, já sob a égide da Missão Francesa de Instrução. É de dezembro de 1908 a missiva que chega de Santos, da parte do piquete de cavalaria, ao secretário Washington Luiz:

Queixa

[...] Nós viemos destacado aqui em Santos no dia 16 [...] somos constantemente perseguidos; somos privados de sahir a rua a qual quer hora do dia ou da noite [...] Pela minima coisa que se fassa esse inferior manda por na sella e tambem já de se baixou o sabre dentro do esquadrão para agredir uma praça [...] 0 senhor alferes do piquete disse às praças que elle tinha deixado 15 praças de infantaria de prontidão armados de clavina e baioneta calada para nos agredir sem que para isso houvesse motivo algum $[\ldots]^{11}$

Percebe-se que a despeito dos ares de profissionalização trazidos com os franceses, embalados pela litania republicana, a relação no dia-a-dia do quartel carreava aspectos passadistas, inerentes a um contexto "decaído" que se pretendia superado - ao menos no discurso oficial, que se jactava, conforme atesta o desejo de Albuquerque Lins, governador paulista em 1909, de formar um "pequeno exército" estadual.

Essas práticas obtusas e arcaicas, proscritas segundo o discurso das autoridades, são diagnosticadas também em Santos pelo praça Alonço Marques, do 2ํㅡatalhão, que, por carta, presta testemunho do descalabro que acometia a companhia daquela cidade. Lembrava ele as ordens que proibiam a presença de "oficiais, inferiores e praças no botequim, taverna etc". ${ }^{2}$ Na missiva, repisava o episódio da delação do 2ํㅗ sargento João de Jesus, flagrado ao entrar na taverna de um espanhol pelo cabo Ernani de Souza, que deu parte ao oficial. Como represália, o sargento Jesus e seus colegas de patente arrumaram 45 dias de detenção para o cabo. "E hoje", complementava, "todos os sargentos sorrindo de contente de ter vingado ao infeliz cabo, o quanto o comte do destacamento não valle porque anda dominado pelos inferiores".

Todavia, as diatribes de praças não se resumiam a queixumes envolvendo necessariamente circunstâncias específicas de trabalho. A convivência diuturna com colegas e superiores 
extravasava da liça do serviço para absorver aspectos privados da rotina dos policiais, afirmando não apenas a porosidade da redoma institucional a elementos estranhos, como também, e mais importante, a falibilidade de que se constituía a estrutura normativa que organizava as relações dos indivíduos na e para com a instituição.

Em 1909, o policial da Força Pública Joaquim José de Oliveira, preso por crime de deserção, escreveu ao secretário da Justiça, Washington Luiz, denunciando o comportamento desabonador do sargento Juvenal Dutra de Oliveira, comandante do destacamento de Dois Córregos, que se aproveitara da prisão do subordinado para seduzir sua esposa. Com sofreguidão e humildade, pelejando a cada frase, expunha seu desespero alertando para a reincidência dessa atitude abominável do sargento, "que envergonha a força pública".

Excelentissmo Senhor doutro peço-vos disculpas da minha ingnorança [...] as famílias da praca deste destacamento aondi minha mulher foi a primeira; eu mi achando prezo a ordem de sinhor tenente coronel commandante e esti enfiliz sargento foi em minha caza as 10 horas da noite e perguntou aqui que mora a mulher do soldado Joaquim; minha mulher respondeu é aqui mesmo. o que o sinhor dezeja elle respondeu para ella seu marido está prezo a sinhora quer que solti elle... mais a sinhora tem que dormir comigo: e como ella não aceito as condição delli elli pegou a mi perseguir [... ] ainda elli dissi que a mulher do soldado que não dormir com elle que preciguia os maridos dellas $[\ldots]^{13}$

Tal relato, além de apontar para o ambivalente processo de formação de solidariedades e rivalidades entre os membros da corporação, ajuda a dar a medida de aspectos laterais do universo institucional, despegados do seu objetivo-fim, mas que compunham o quadro mais amplo de conexões entre os "mundos" interno e externo. No caso, tratamos da vida familiar dos policiais e de suas copiosas alusões na documentação pesquisada, ainda que, oficialmente, o discurso institucional, acompanhado dos regulamentos, leis e portarias, permanecessem silenciosas quanto ao imbricamento muitas vezes conflituoso das duas esferas institucionais - a polícia e a família. Encontramos algumas prescrições idealizadas, porém não sistemáticas, que asseveravam o benefício ou o malefício da vida familiar para o bom andamento do serviço. Em muitas ocasiões, havia dificuldade de se arregimentar voluntários, pois a administração da polícia não podia garantir a proximidade com a família durante o tempo de serviço (Rosemberg, 2010).

Em alguns casos, a família acompanhava o soldado, sob o condicionante do lastro financeiro de cada um, uma vez que o soldo diminuto dificultava o sustento de muitas bocas. Caso contrário, a solução estava em se apelar para o beneplácito dos superiores ou acionar um pistolão bem colocado, solicitando-se transferência para perto dos seus ou a manutenção em destacamento mais conveniente, a despeito da exigência legal. 
Aureliano de Oliveira, em 1901, também destacado em Ribeirão Preto, escreveu ao chefe de polícia solicitando seu recolhimento para a capital, pois alegava se encontrar enferma sua "ansiana mãi", "a quem não ha outros meios para regar a sua vida, se não for o meu soldo, mais achando-me assim tão retirado della não poderei socorrer como tenho obrigação nas suas necessidades [...]"14

Se inquietações familiares davam cor à correspondência epistolar, dificuldades em torno do trem de vida dos policiais açularam a pena e a tinta. Sabe-se que o policial militar esteve equiparado, em relação aos estipêndios, à base dos trabalhadores sem qualificação (Rosemberg, 2010). 0 salário baixo e as exigências severas do serviço faziam da opção pela farda uma ocupação intermitente, que não provia expectativas de carreira duradoura e dificultava o preenchimento, pela administração, do contingente legal previsto (Rosemberg, 2009). Nas missivas, a ladainha que deplorava a carestia que oprimia se transformava em expediente de persuasão.

Num exemplo raro disponível na documentação, encontra-se uma carta do soldado Demerval Ribeiro do Prado escrita de Campinas à sua mãe, residente em Areias, no Vale do Paraíba. Datada de 4 de julho de 1907, a missiva dá o tom da vida dura:

Minha presada mamãe

[...] ahi vai 10.000 dez mil reis para a sra; não mando mais porque a sra sabe que aqui tudo é muito caro, pois so de uma sala pago trinta mil réis por meiz. tenho mulher e filhos para sustentar comforme a sra é sabedoura. sei que dez mil reis não chega para nada, mas o que hei de fazer [...]

sem mais lembrança nossas, seu estimado filho ${ }^{15}$

A carta de Demerval estava apensada a outra da lavra de Joanna Maria da Conceição, a dita genitora, em que esta dizia - talvez com auxílio alheio - lutar "com grandes sacrifícios para a sua subsistencia, devido a sua já adiantada idade e viver constantemente enferma". Solicitava a transferência do filho para junto de si, em Areias, no Vale do Paraíba. Não obstante os apelos, sua solicitação foi indeferida.

Implicações de ordem econômica também moveram o alferes João Bastos de Souza a escrever carta pessoal ao chefe de polícia, em 1893, solicitando sua transferência para 0 interior do estado, "em vista de eu me achar bastante atrazado em meus debitos queiro economizar para assim poder satisfaser o meu credito sua exa. sabe que aqui a vidda esta cara por demais"16. Para desgosto do alferes, a despeito de atender ao protocolo da submissão pessoal, do afeto e da intimidade, postura deslocada da praxe burocrática, sua solicitação entrou na fila, aguardando uma "oportunidade". 
Como visto, mover a máquina da burocracia implicava, de um lado, o domínio de vários repertórios que envolviam o conhecimento das regras e prescrições oficiais. De outro, quando os canais adequados não estavam disponíveis, impunha-se articular estratégias alternativas estranhas ao sistema formal, mas que configuram a faceta opaca, nebulosa do funcionamento de toda organização, em especial da polícia (Monjardet, 2001).

\section{Pedidos de baixa}

$\mathrm{O}$ utra das motivações que animavam os policiais a recorrer à correspondência epistolar em vez dos meios oficiais eram os pedidos de baixa. Isso porque, uma vez engajado, a liberação do serviço policial acontecia em casos muito específicos: legalmente, a baixa se dava em decorrência do termo do prazo de engajamento (normalmente de quatro anos), da apresentação de substituto idôneo (condicionada à anuência da administração), do desligamento por motivo de saúde (a ser aferido pelo médico da corporação), ou ainda "sem declaração de motivo", quando a justificativa para a concessão partia das prerrogativas do chefe de polícia ou do secretário da justiça, dependendo da competência legal. A rubrica do "sem motivo" era a preferida dos policiais, já que não manchava a fé de ofício com um desabono de comportamento ou uma tacha no histórico médico. Pois afora as circunstâncias lícitas, a baixa se impunha quando a conduta disciplinar do praça extrapolava os limites do tolerável, levando à sua exclusão por "incorrigível". Conquistar a baixa do serviço, portanto, configurava uma tarefa importante e complexa da vida institucional do policial de menor patente, considerando-se que raramente 0 recruta ingressava na polícia com a expectativa de uma carreira promissora (Rosemberg, 2009).

As cartas funcionavam como uma espécie de reforço para as demandas, ao mobilizar recursos privilegiados cuja eficácia mostrava-se mais certeira do que a dos meios comuns. Muitas vezes as recomendações partiam de "padrinhos" bem relacionados com as autoridades, que enviavam bilhetes em pomposos papéis de carta ou garatujavam algumas linhas no verso de um cartão de visitas, invocando amizades de longa data ou a promessa de favores trocados. Nesses casos, a abordagem, francamente íntima, tomava a autoridade em pé de igualdade, em posição muito diferente da subserviência prestada pelos praças, com reflexos flagrantes de linguagem, como se pode observar na carta abaixo, enviada, em maio de 1909, por um certo João Baptista de Mello Peixoto ao secretário da Justiça, Washington Luiz, para quem dispensa, aliás, as formalidades de tratamento nos pronomes pessoais empregados:

Minhas atenciosas saudações. Não tenho remédio senão incomodá-lo com histórias de soldados. Eles prendem-se a famílias do lugar, estas apertam-me e não há jeito senão amolar os amigos. Lá vai mais um caso. 0 soldado Ernesto Alves Pereira, 137, da 4ª companhia do 
2ํ batalhão (creio), destacado em S. Carlos, desertou por doente ou cousa que o valha: o tal não presta para soldado; sofre de fígado e é frouxo. Foi preso e recolhido ultimamente ao xadrez em S. Paulo e aí aguarda conselho. A família muito pobre e numerosa pelas ligações nesta cidade, não me sai da porta: não haverá um meio sem ofensa da lei e da disciplina de sapecar esse sujeito e o largarem? ${ }^{17}$

Em outras ocasiões cabia aos policiais escrever - de próprio punho ou a rogo - aos superiores aludindo a relações familiares, de amizade ou geográficas, próximas ou mais distantes, não sem antes, como dito, dar especial esmero ao tratamento empolado, que não raro descambava para uma formalidade canhestra, muito por causa da afetividade dramática do conteúdo, e da marcação, bem esclarecida, da posição social de cada um.

José Antonio da Cruz, cabo enfermeiro destacado em Santos, enviou ao secretário de Justiça seu pedido de baixa em 16 de dezembro de 1907, junto com uma carta do delegado de Campinas, corroborando a solicitação. Escrevia ele: "A justificativa do meu pedido para vos tão insignificante tem para mim valores exuberantes", uma vez que "colho o quasi insufficiente para subsidio daquelles que enfim o fazem render [...]. ${ }^{18}$

0 aperto financeiro do enfermeiro justificava o pedido de baixa antecipada em dois anos. Apoiado na recomendação do comandante do Corpo de Bombeiros, que não via qualquer inconveniente, a baixa the foi concedida.

Já o sargento Guilherme Prazeres optou por recorrer a um intermediário a fim de obter sua baixa do serviço. Escreveu em outubro de 1908 a seu "protetor", um certo Alvaro de Queiroz, para que intercedesse junto ao secretário de justiça, por encontrar-se "bastante doente dos intestinos e necessitar de retirar-me para fora deste Estado; não só isto, pois tenho também a minha mulher sofrendo gravemente do útero, devido a um parto prematuro [...]". Contratempos financeiros também oprimiam o inferior, cuja esposa vivia em estado "paupérrimo". ${ }^{19}$

Os pedidos de baixa quase sempre se respaldavam em dramas financeiros ou familiares. De Ribeirão Pires, cidade nos bordos da capital, o anspeçada Arthur Mello Oliveira escreveu ao secretário da Justiça e Segurança Pública, Washington Luiz, em 1907, requerendo sua exclusão com o fito de retornar a Minas Gerais, onde era arrimo de família. Juntava, à guisa de reforço, uma carta que recebera da irmã Zulmira em setembro de 1907, que de Itajubá relatava as dificuldades provenientes desde o passamento do pai e relembrava ao irmão que era solteira e carregava em sua companhia três irmãos menores:

Sendo voce bem voce bem sabes que es o unico irmão homem da família [...] vendo assim, çe podes tiral a farda fará e vim cuidar em nossas irmãzinhas pequeninas que nescessitam de amparo acceite muitas lembranças de Adelina e de todo nos d"casa.

Sua Irmam que vos estima ${ }^{20}$ 
Nessa missiva familiar, destaca-se o papel que passava a cumprir, após a morte do pai, Arthur, o primogênito, único homem entre os irmãos. Se, como mostra a literatura, as experiências das dinâmicas familiares não se esgotavam no padrão imposto pela cartilha patriarcal, as representações coletivas espelhavam as exigências da norma: o cumprimento tal-e-qual dos papéis atribuídos a cada um pela expectativa majoritária (Corrêa, 1981). Na carta de Zulmira, a distribuição das funções aparece muito bem cristalizada, nos limites do modelo idealizado, a reproduzir o construto do discurso dominante. O lugar do irmão homem, que substitui o pai morto; a irmã solteira, impedida pelo bom tom de chefiar a família. Como obstáculo para o retorno de Arthur, erguia-se a farda. E, ao que parece, o apelo de Zulmira sensibilizou o secretário, que, incontinenti, decretou a baixa do policial.

\section{POLICIAIS NA PRISÃO}

$\mathrm{N}$ o infortúnio de se ver enredado com a severidade do regulamento disciplinar ou de pisar os calos de chefes intransigentes, a detenção na carceragem da polícia era destino indefectível. Nesses casos, apelava-se aos superiores mais distanciados, implorando-lhes pela revisão do caso e o alívio no tempo de martírio. Alegava-se a injustiça do ato prisional, atrelando-o à perseguição de comandantes e ao abuso de autoridade.

Em maio de 1908, os policiais Arthur Leandro de Queiroz, Fernando Damas de Souza, Leocadio Ribeiro, Clementino da Silva, Pedro de Almeida, Marçal Veríssimo de Almeida e José Francisco da Silva enviaram uma carta conjunta ao presidente do estado, Albuquerque Lins, em que vinham "mui respeitosamente aos pés de V. Exa por meio desta pedir-vos o vosso digno apoio no sentido de nos perdoar de uma prisão em que se achamos por parte de nossa ignorância" . ${ }^{21}$ Em apuração do pedido, o comandante do º Batalhão, Domingos Quirino Teixeira, informava os crimes cometidos pelos praças, que iam de insubordinação à deserção, desaconselhando a mercê.

Em outras ocasiões, o pedido de comiseração vinha de um familiar do soldado preso. Em 1906, Maria Rosa, "pobre mulher mãi de tres filhos" residente em Guaratinguetá, no Vale do Paraíba, dirigiu-se em carta ao chefe de polícia, implorando, "em baixo de lagrimas", pela soltura de seu marido, o policial Manoel Thomas de Souza, "porque meus sofrimentos e bastante com os meus pobre filinhos que me vejo achorar por fartar o pão". 22 Não se sabe bem por que meios - já que houve interferência de um certo Augusto de Meireles Reis, que procede aos pedidos - o soldado detido na capital foi transferido para Guaratinguetá, atendendo-se às súplicas da esposa em flagelo.

Em agosto de 1884, o guarda da Companhia de Urbanos Benedicto Antonio Pinto, preso havia seis dias no xadrez da estação de urbanos de Santa Cecília, escreveu ao chefe 
de polícia clamando por perdão, uma vez que sua mulher e filhos estavam "enfermos", sem condições de comprar remédios: "Porque em V. Exa está a minha sortura, porque eu estou à sua disposição [...] Se eu fiz alguma coisa, V. Exa fará o favor de me descurpar, que é a primeira vez. 0 suplicante espera de V. Exa ser atendido".23

\section{CONSIDERAÇÕES FINAIS}

polícia junto com a justiça são, por excelência, as instituições responsáveis por inscre-
ver autoritariamente o discurso alheio, organizando-o nos limites de amarras de poder muito bem definidas, em que a posição hierárquica do notário e da testemunha define a legitimidade e a validade da fala (Corrêa, 1983). A maleabilidade natural da oralidade, quando reduzida ao termo da ritualística jurídico-policial, vem enquadrada, de antemão, em fórmulas rígidas de expressão que suprimem o valor espontâneo. Os fragmentos epistolares que vazaram dos arquivos funcionam, em parte, como a subversão desse princípio, pois lançam mão de um expediente proscrito pela burocracia comme il faut, que exige em sua constituição de princípios a obediência cega às fórmulas determinadas para a comunicação entre os escalões, seja na transmissão das ordens funcionais, de cima para baixo, seja nas demandas de sentido inverso (Weber, 1947). 0 caminho na escada burocrática deve ser imediato, sem pular degraus ou desafiar comandos. A carta, além de atalhar o percurso normativo e a distância física que separa o comando da base, rompe, em seu formato, com as formalidades engessadas dos instrumentos de comunicação disponíveis - o ofício.

Ao contrário das palavras ditas, que se esvanecem imediatamente, da tinta que se deita em papel corre-se o risco da perpetuidade, como atestam as cartas de policiais que sobreviveram no Arquivo, corroborando, assim, uma memória que se revela mais renitente ao esquecimento e que desguarnece a carapaça que se almeja inviolável da instituição policial. Temos uma ironia, portanto. A polícia munida de sua aversão à transparência, fiadora do segredo como um insumo capital e essencial ao ofício de que se desincumbe (Brodeur, 2003; Monjardet, 2005), guardou sem muito pundonor - nas cartas de seus agentes - o calcanhar de aquiles de sua vulnerabilidade.

Ao se desvelarem flagrantes materiais da "humanidade" que dá estofo à instituição, passa-se a se considerar a amplitude de relações que se entrelaçam na construção cotidiana de uma instituição, em que concorrem vetores díspares, ambíguos e conflitantes - que têm a ver com as formas propriamente organizacionais, as demandas que fazem funcionar a instituição e os interesses de uma profissão (Monjardet, 2001). No fim das contas, as cartas permitem entrever, numa intimidade embuçada, aspectos recônditos da vida desses policiais-trabalhadores. 
0 recurso a esse expediente, ainda que rotinizado e inscrito numa tradição que modula a rígida normativa institucional, apresenta-se como exceção, uma vez que as cartas pessoais são insuetas diante da miríade dos documentos meramente protocolares encontradiços nas latas de polícia. Verdade que por trás das meras indicações burocráticas, que ditam uma baixa ou um deslocamento, pode ocultar-se uma cadeia de táticas informais que percutem a carapaça organizacional. É justamente a montagem ambivalente do universo da burocracia policial, construído por múltiplas redes de interdependência, no intestino da hierarquia policial e entre os indivíduos e a instituição, o ponto que gostávamos de apontar com este trabalho.

\section{NOTAS}

1 Carta de Joaquim José de Araújo ao Secretário de Segurança Pública e do Negócio Jurídico de São Paulo, em 24 de fevereiro de 1909. Arquivo Público do Estado de São Paulo (AESP), co3169.

2 As balizas do recorte cronológico compreendem, em seu início, a data da reorganização das polícias de São Paulo pós-Guerra do Paraguai, quando a Guarda Nacional, até então igualmente responsável pelo policiamento, adquire função meramente decorativa (Castro, 1979). Na outra ponta, o termo está atrelado à descontinuidade da série documental no AESP, que se interrompe em 1915. 0 lapso temporal de 45 anos, com uma mudança de regime no meio, permite acompanhar as quebras e permanências das práticas policiais inscritas nas cartas.

3 Devemos o pioneirismo dessa história social da polícia aos ingleses. Entre outros, ver Storch (1975, 1976); Emsley (1996, 2000); Schpayer-Makov (2002); Brogden (1991); Klein (2010). Para a França, ver Houte (2010); Deluermoz (2012); Bérlière; Levy (2010). Em Bérlière; Denys; Kalifa; Milliot (2008), há artigos que se referem a outros países europeus [ver Cadeschi (2008); Weinhauer (2008); Leßmann-Faust (2008); Theodorson (2008), Dunnage (2008)]. Para os Estados Unidos e Canadá, ver Miller (1999); Monkkonen (2004); Marquis (1987). Para a América Latina, ver Bretas (1997, 1997a); Mauch (2011); Galeano (2015); Cárdenas (2013).

4 A atualização da fórmula de tratamento calava fundo na administração policial. Deixar no passado modelos obsoletos, por mais simbólicos que fossem, fazia parte das preocupações da Secretaria de Segurança Pública. Em 1906, a mesma secretaria admoestou em ofício o delegado de polícia de Capivari para que "encerrasse os seus ofícios com a fórmula 'saúde e fraternidade' e não outra qualquer desusada na correspondência oficial do Estado". Oficio do chefe da 3a Seção da Secretaria de Justiça e Segurança Pública ao secretário de justiça, em 30 de outubro de 1906. AESP, c03098.

5 Carta de Bento José Alves, anexa a ofício do comandante do Corpo Policial Permanente ao Presidente da província de São Paulo, em 20 de janeiro de 1888. AESP, co2343.

6 Carta de Renato Ferreira Gonçalves ao Chefe de Polícia de São Paulo, em 11 de maio de 1901. AESP, c02971.

7 São Paulo. Decreto 437, de 20 de março de 1897, art. 379: "Os officiaes e praças da brigada policial não podem fazer representações collectivas e devem evitar, quanto possivel, as manifestações collectivas de agrado aos seus superiores, por enfraquecerem de algum modo a disciplina militar".

8 Carta de soldado anônimo ao chefe de polícia, em 10 de setembro de 1872. AESP, co2548. 
9 Abaixo-assinado dos praças do destacamento de Araras anexo a ofício do comandante do CPP ao chefe de polícia, em 21 de dezembro de 1883. AESP, co2623.

10 Abaixo-assinado do destacamento de Ribeirão Preto ao chefe de polícia, em 25 de fevereiro de 1888. AESP, co2691.

11 Carta anônima ao Secretário de Segurança Pública e do Negócio Jurídico de São Paulo, em 21 de dezembro de 1908. AESP, c03151.

12 Carta de Alonço Marques ao Secretário de Segurança Pública e do Negócio Jurídico de São Paulo, em 08 de agosto de 1907. AESP, c03138.

13 Carta de Joaquim José de Souza ao Secretário de Segurança Pública e do Negócio Jurídico de São Paulo, em 09 de abril de 1909. AESP, c03169.

14 Carta de Aureliano de Oliveira ao Chefe de Polícia de São Paulo, em 07 de novembro de 1901. AESP, co2962.

15 Carta de Demerval Ribeiro do Prado, anexa à carta de Joanna Maria da Conceição ao Secretário de Segurança Pública e do Negócio Jurídico de São Paulo, em 17 de julho de 1907. AESP, c03127.

16 Carta do alferes João Bastos de Souza ao chefe de polícia, em 01 de janeiro de 1883. AESP, co2762.

17 Carta de João Baptista de Mello Peixoto, anexa a ofício do comando da Força Pública de São Paulo ao Secretário de Segurança Pública e do Negócio Jurídico de São Paulo, em 05 de maio de 1909. AESP, co3171.

18 Carta de José Antonio da Cruz ao delegado de polícia de Campinas, em 16 de dezembro de 1907. AESP, co3121.

19 Carta de Guilherme Marques Prazeres a Álvaro de Queiroz, em 22 de outubro de 1908. AESP, co3146.

20 Carta de Arthur Mello de Oliveira ao Secretário de Segurança Pública e do Negócio Jurídico de São Paulo, em 08 de outubro de 1907. AESP, c03138.

21 Carta de Arthur Leandro de Queiroz, Fernando Damas de Souza, Leocadio Ribeiro, Clementino da Silva, Pedro de Almeida, Marçal Veríssimo de Almeida e José Francisco da Silva ao presidente do estado, em 02 de maio de 1908. AESP, c03144.

22 Carta de Maria Rosa ao comandante da Força Pública de São Paulo, anexa a ofício de comandante da Força Pública ao chefe de polícia, em 21 de junho de 1906. AESP, c03099.

23 Carta de Benedicto Antonio Pinto ao chefe de polícia, em 09 de agosto de 1884. AESP, co2640.

\section{REFERÊNCIAS BIBLIOGRÁFICAS}

AMARAL, A. B. A Missão Francesa de instrução da Força Pública de São Paulo, 1906-1914. Separata da Revista do Arquivo Municipal, São Paulo, 1968.

BEATTIE, Peter. Tributo de sangue - Exército, honra, raça e nação no Brasil, 1864-1945. São Paulo: Edusp, 2009.

BERLIÈRE, Jean-Marc \& LÉVY, René. Le témoin, le sociologue et l'historien - quand les policiers se mettent à table. Paris: Noveau Monde, 2010. 
; DENYS, Catherine; KALIFA, Dominique \& MILLIOT, Vincent (dir.). Métiers de police - être policier en Europe, XVIIle-XXe siecle. Rennes: PUR, 2008, pp. 97-110.

BRETAS, Marcos Luiz. Ordem na cidade - o exercício cotidiano da autoridade policial no Rio de Janeiro: 1907-1930. Rio de Janeiro: Rocco, 1997.

A guerra das ruas: povo e polícia na cidade do Rio de Janeiro. Rio de Janeiro: Editora do Arquivo Nacional, 1997a.

BRODEUR, Jean-Paul. Les visages des polices - pratiques et perceptions. Montreal: PUM, 2003.

BROGDEN, Michael. On the Mersey beat: policing Liverpool between the wars. Oxford: Oxford University Press, 1991.

CÁRDENAS, Vania. El orden gañán. Historia social de la policía: Valparaíso 1896-1920. Concepción: Ediciones Escaparate, 2013.

CHALHOUB, Sidney. Diálogos políticos em Machado de Assis. In: CHALHOUB, Sidney \& PEREIRA, Leonardo Affonso de M. (org). A História contada. Rio de Janeiro: Nova Fronteira, 1998, pp. 95-122.

CORRÊA, Mariza. Repensando a família patriarcal brasileira - Notas para o estudo das formas de organização familiar do Brasil. Caderno de Pesquisa, n. 37, maio de 1981, pp. 5-16.

Morte em família - representações jurídicas de papéis sexuais. Rio de Janeiro: Graal, 1983.

EMSLEY, Clive. The Policeman as worker: a comparative survey c. 1800-1940, International Review of Social History, n. 45, 2000.

FOUCAULT, Michel. A escrita de si. In: Ditos e escritos - ética, sexualidade e política. V. 5. Rio de Janeiro: Editora Forense Universitária, 2012, pp. 145-162.

GALEANO, Diego. 0 ofício inconfessável: policiais, ordem urbana e mercado de trabalho na cidade de Buenos Aires, 1867-1880, Revista do Arquivo Geral da Cidade do Rio de Janeiro, n. 9, 2015, pp. 191-209.

GOMES, Ângela de Castro. Escrita de si, escrita da História: a título de prólogo. In: (org.). Escrita de si, escrita da História. Rio de Janeiro: FGV Editora, 2004.

HOUTE, Arnaud-Dominique. Le métier de gendarme au XIXe siècle. Rennes: PUR, 2010.

KLEIN, Joanne. Invisible men - the secret lives of police constables in Liverpool, Manchester and Birmingham, 1900-1939. Liverpool: Liverpool University Press, 2010.

LEVY, Giovanni. Usos da biografia. In: FERREIRA, Marieta de Moraes e AMADO, Janaína (org). Usos \& abusos da História Oral. Rio de Janeiro, 2009, pp. 167-182.

LORIGA, Sabina. Soldats - um laboratiore disciplinaire: I'armée piémontaise au XVIIle siècle. Paris: Les Belles Letres, 2007.

MALATIAN, Teresa. Narrador, registro e arquivo. In: PINSKY, Carla Bassanezi \& LUCA, Tania Regina de (orgs). O historiador e suas fontes. São Paulo: Editora Contexto, 2009, pp. 195-223.

MARQUIS, Greg. Working men in uniform: the early twentieth-century Toronto Police, Histoire Sociale - Social History, vol. XX, n. 40, novembro 1987, pp. 259-277.

MAUCH, Cláudia. Dizendo-se autoridade: polícia e policiais em Porto Alegre, 1896-1929. Tese de Doutorado. Porto Alegre: UFRGS, 2011. 
MILLER, Wilbur. Cops and bobbies - police authority in New York and London, 1830-1870. Ohio: Ohio State University, 1999.

MONJARDET, Dominique. O que faz a polícia. São Paulo: Edusp, 2001.

Gibier de recherche, la police et le projet de connaître, Criminologie, vol. 38, n² 2, 2005, pp. 13-37.

ROSEMBERG, André. La grève de la Force publique de São Paulo (13 et 14 janvier 1961), Vingtième siècle Revue d'Histoire, n. 128, outubro-dezembro 2015, pp. 29-44.

. Rotina, trabalho e (in)disciplina: uma leitura das Ordens do Dia da Força Púbica paulista (1900-1920). In: CARNEIRO, Deivy Ferreira; BRETAS Marcos Luiz; ROSEMBERG, André (orgs). História, violência e criminalidade - reflexões temáticas e narrativas regionais. Uberlândia: EDUFU, 2015, pp. 175-196.

. A greve pelas oito horas em Santos (1908): em busca do inimigo imaginário, História \& Perspectivas, n. 49, jul-dez 2012, pp. 17-40.

. Retrato policial: um perfil da praça de polícia em São Paulo (1868-1896), História, vol. 29, n. 2, 2012a, pp. 95-115.

De chumbo e festim - uma história da polícia paulista no final do Império. São Paulo: EDUSP, 2010.

. Para quando o calo aperta - os trabalhadores-policiais do Corpo Policial Permanente de São Paulo no final do Império, Locus: revista de história, v. 15, n. 1, 2009, p. 77-90.

SHPAYER-MAKOV, Haia. The making of a policeman: a social history of a labour force in metropolitan London, 1829-1914. Burlington: Ashgate, 2002.

STORCH, Robert. The Policeman as domestic missionary, Journal of Social History, vol. 9, 1976, pp. 471-509.

WEBER, Max. The theory of social and economic organization. Nova York: The Free Press, 1947. 